\title{
PENDAMPINGAN PROGRAM FARKOM (FARMAKOLOGY AND COMPLEMENTARY THERAPY) UNTUK PASIEN DAN KELUARGA PENDERITA KANKER PAYUDARA
}

\author{
Indah Sri Wahyuningsih ${ }^{1}$, Fitria Endah Janitra ${ }^{2}$, Asih Puji Lestari ${ }^{3}$ \\ Universitas Islam Sultan Agung Semarang \\ korespondensi email: indah.unissula@gmail.com \\ ${ }^{2}$ Universitas Islam Sultan Agung Semarang \\ email: fitria.janitra@gmail.com \\ ${ }^{3}$ Universitas Islam Sultan Agung Semarang \\ email: asih_11@unissula.ac.id
}

\begin{abstract}
Breast cancer patients need to get palliative care to improve their quality of life. Family existence becomes an important role for breast cancer sufferers to fulfill physical and psychological health. Palliative care can be given to patients in the form of complementary and pharmacological therapy (FARKOM). FARKOM's community service program aims to improve family knowledge and abilities in the care of family members with breast cancer and support for taking medication control. The target of this community service activity is to involve five families with breast cancer members in the Bandarharjo Village. The methods of this activity include lectures on the Farkom program (Pharmacology and complementary therapy), demonstrations of progressive muscle relaxation techniques and how to make beetroot juice, simulations by grouping participants according to family members and practicing, then monitoring and evaluating related to the Farkom program. Based on the pre-test and post-test results after being given treatment, there was an increase in the percentage value, namely a $25 \%$ increase in progressive muscle relaxation exercises, herbal juice production increased $30 \%$ and monitor filling schedule for taking medication increased $30 \%$. Thus, this mentoring activity can be said to be successful because it can increase the knowledge and ability of participants in participating in community service activities.
\end{abstract}

Keywords: breast cancer; farkom; progressive muscle relaxation.

\begin{abstract}
ABSTRAK
Pasien kanker payudara perlu mendapatkan perawatan paliatif untuk meningkatkan kualitas hidupya. Keberadaan keluarga menjadi peran penting bagi penderita kanker payudara untuk memenuhi kesehatan fisik dan psikologis. Perawatan paliatif dapat diberikan pada pasien berupa terapi komplementer dan farmakologi (FARKOM). Program pengabdian masyarakat FARKOM bertujuan untuk meningkatkan pengetahuan dan kemampuan keluarga dalam perawatan anggota keluarga dengan kanker payudara dan dukungan terhadap kontrol minum obat. Target pada kegiatan pengabdian ini adalah melibatkan keluarga yang memiliki anggota dengan penyakit kanker payudara di Kelurahan Bandarharjo sebanyak lima keluarga. Metode kegiatan ini meliputi ceramah program Farkom (Farmakologi dan complementary therapy), demonstrasi teknik progressive muscle relaxation dan cara membuat jus buah bit,
\end{abstract}


simulasi dengan mengelompokkan peserta sesuai anggota keluarga dan mempraktekkan, selanjutnya memonitor dan evaluasi terkait program Farkom. Berdasarkan hasil pretest dan posttest setelah diberikan treatment terjadi peningkatan nilai persentase yaitu peningkatan $25 \%$ pada latihan progressive muscle relaxation, pembuatan jus herbal meningkat $30 \%$ dan monitor pengisian jadwal minum obat meningkat 30\%. Dengan demikian, kegiatan pendampingan ini dapat dikatakan berhasil karena mampu meningkatkan pengetahuan dan kemampuan peserta dalam mengikuti kegiatan pengabdian masyarakat.

Kata Kunci: kanker payudara; farkom; relaksasi otot progresif.

\section{PENDAHULUAN}

Kanker merupakan salah satu penyebab kematian tertinggi dan menjadi masalah kesehatan di dunia maupun di Indonesia. Prevalensi kanker di Indonesia meningkat dari tahun 2013 sebanyak 1.4 per 1000 penduduk (Wahidin, 2015). Prevalensi kanker payudara di Indonesia mencapai 0,5\% dari 1000 perempuan sedangkan Angka kejadian tertinggi di Indonesia untuk laki-laki adalah kanker paru yaitu sebesar 19,4 per 100.000 penduduk dengan rata-rata kematian 10,9 per 100.000 penduduk, yang diikuti dengan kanker hati sebesar 12,4 per 100.000 penduduk dengan rata-rata kematian 7,6 per 100.000 penduduk (Manafe, 2019). Pasien yang menderita kanker perlu melakukan terapi pengobatan dalam upaya penyembuhannya. Salah satu pengobatan yang dianjurkan yaitu kemoterapi.

Kemoterapi adalah terapi anti kanker untuk membunuh sel-sel tumor dengan menganggu fungsi dan reproduksi sel yang bertujuan untuk penyembuhan, pengontrolan, dan paliatif. Kemoterapi bisa menimbulkan dampak fisiologis maupun psikologis (Rahayuwati et al., 2017). Dampak fisiologis yang bisa terjadi yaitu rasa lelah, lesu, kerontokan rambut, gangguan usus dan rongga mulut seperti mual muntah, mukositis rongga mulut, gangguan sumsum tulang belakang, kemandulan, gangguan menstruasi \& menopause serta gangguan pada organ lain. Jumlah pasien kanker semakin meningkat sehingga diperlukan perawatan paliatif jangka panjang untuk meminimalkan permasalahan yang terjadi pada pasien tersebut. Permasalahan yang terjadi pada pasien kanker diataranya yaitu kecemasan, resiko kekambuhan dan status perkembangan kanker, manajemen kesehatan, masalah sosial, keuangan dan masalah seksual. Peran perawat adalah dapat memberikan perawatan paliatif untuk meningkatkan kualitas hidupnya.

Perawatan paliatif bertujuan untuk meningkatkan kualitas hidup pasien dan memberikan dukungan bagi keluarga yang menghadapi masalah yang berhubungan dengan kondisi pasien dengan mencegah dan mengurangi penderitaan melalui identifikasi dini, penilaian yang seksama serta pengobatan nyeri dan masalah-masalah lain, baik masalah fisik, psikososial, spiritual dan pelayanan masa dukacita bagi keluarga (Pratitis, 2016). Perawat adalah salah satu anggota tim yang biasanya memiliki kontak terlama dengan pasien dan berperan penting dalam penerapan implementasi perawatan 
paliatif. Salah satu perawatan paliatif untuk meningkatkan kualitas hidup pasien kanker adalah dengan pemberian terapi komplementer (Friyanti, 2015).

Terapi komplemeter sebagai pengembangan terapi tradisional dan ada yang diintegrasikan dengan terapi modern yang mempengaruhi keharmonisan individu dari aspek biologis, psikologis, dan spiritual (Widyatuti, 2008). Jenis terapi komplementer ada dua yaitu terapi invasif dan non invasif. Terapi non invasif yang dapat diterapkan untuk pasien kanker adalah terapi jus dan progressive muscle relaxsation (Mitchell \& Chaboyer, 2010) (Onishi, 2016). Keseluruhan permasalahan diatas biasanya juga melibatkan aspek sosial, hubungan perkawinan, sosial dan ekonomi. Kompleksnya permasalahan pasien kanker, baik permasalahan fisik maupun masalah psikososiospiritual lainnya, apabila tidak ditangani secara komprehensif akan menurunkan kualitas hidup pasien yang mungkin hanya tinggal beberapa minggu sampai beberapa bulan lagi. Mayoritas pasien kanker di Keluarahan Bandarharjo merupakan pasien kanker payudara. Tujuan utama perawatan pasien kanker pada fase paliatif adalah mengoptimalkan peningkatan kualitas hidup pasien dengan mengontrol gejala-gejala fisik yang timbul baik karena progresifitas kanker atau efek kemoterapi, dan memberikan perhatian terhadap pemenuhan kebutuhan psikososiospiritual (Avisha et al., 2017).

Manajemen keperawatan paliatif berbasis family centered care merupakan model perawatan yang didasarkan pada prinsip yang menganggap keluarga sebagai satu-satunya aspek penting yang terdiri dari kesehatan fisik dan psikologis dan mempunyai tiga elemen kunci yaitu hubungan yang saling menghormati, kolaborasi serta dukungan (Wahyuningsih et al., 2019). Family centered care merupakan terobosan baru dalam perawatan paliatif. Seperti yang telah diketahui bahwa peran dan dukungan keluarga akan sangat mempengaruhi keberhasilan perawatan pasien khususnya pasien terminal (Husni et al., 2015). Program Manajemen Keperawatan berbasis Family centered care pada pasien kanker meliputi dukungan keluarga terhadap pendampingan pengobatan dan terapi komplementer bagi pasien kanker (Janitra et al., 2020). Kegiatan pendampingan pengobatan meliputi pembuatan jadwal pengawas minum obat yang benar, sedangkan terapi komplementer meliputi program progressive muscle relaxation dan terapi jus herbal bagi penderita kanker untuk meningkatkan kualitas hidupnya (Larasati et al., 2019).

Berdasarkan studi pendahuluan yang dilakukan di Kelurahan Bandarharjo terdapat 5 orang yang mengalami kanker payudara, 1 orang tidak mendapat perawatan yang baik karena faktor biaya dan keluarga, 2 orang mendapat tindakan mastektomi, 1 orang sudah dinyatakan sembuh setelah menjalani kemoterapi dan radiasi, serta dinyatakan sebagai survivor cancer, 1 orang dengan mastektomi dan sekarang menjalani kemoterapi untuk kanker servik. Tujuan dari kegiatan pengabdian masyarakat ini adalah untuk meningkatkan pengetahuan dan kemampuan keluarga yang nantinya akan 
diterapkan dan dipraktekkan oleh anggota keluarga masing-masing yang memiliki pasien kanker payudara. Selain itu keluarga juga dapat memberikan dukungan kontrol obat dan terapi.

\section{METODE PELAKSANAAN}

Metode dalam pelaksanaan pengabdian masyarakat ini diantaranya melalui ceramah, demonstrasi, simulasi, monitoring dan evaluasi.

1. Ceramah

Peserta mengikuti kegiatan pemaparan mengenai program FARKOM (Farmakologi dan Complementary Therapy) dan berdiskusi dan tanya jawab mengenai materi yang dipaparkan.

2. Demonstrasi

Peserta melihat cara mempraktekkan progressive muscle relaxation dan cara membuat jus buah bit. Tujuannya agar peserta mampu memahami terapi fisik untuk keluarganya dan mampu memahami cara pembuatan jus buah bit.

3. Simulasi

Simulasi dilakukan bertujuan agar peserta terampil dan mampu melakukan teknik progressive muscle dan membuat jus. Peserta dikelompokkan sesuai anggota keluarganya dan mempraktekkan langkah- langkah progressive muscle relaxation, pemuatan jus dan pengisian jadwal minum obat.

4. Monitor dan evaluasi

Peserta dapat berkonsultasi dengan tim pelaksana terkait latihan progressive muscle relaxation, pembuatan jus buah bit dan pengisian monitoring obat untuk pasien kanker. Tim pelaksana dapat mengevaluasi dan memonitoring secara langsung pada peserta (kelompok keluarga). Proses monitoring dan evaluasi penerapan FARKOM terus dilakukan selama periode kegiatan pengabdian.

\section{HASIL DAN PEMBAHASAN}

Kegiatan pengabdian masyarakat ini dilakukan di Kelurahan Bandarharjo, Semarang Utara. Sesi pengabdian masyarakat FARKOM ini diawali dengan memberikan pengetahuan dasar mengenai program FARKOM yang meliputi permasalahan pasien kanker, terapi kompelementer yaitu latihan progressive muscle relaxation, pembuatan jus buah bit dan pengisian monitoring obat. Topik terapi komplementer masing-masing untuk peserta, sehingga peserta diberikan edukasi dan sosialisasi terkait FARKOM. Sesi awal ini juga berhasil membentuk kelompok keluarga peduli kanker. Sesi kedua dengan melakuan demonstrasi gerakan latihan progressive muscle relaxation, pembuatan jus buah bit dan pengisian monitoring obat. 
Tabel 1. Nilai sebelum dan setelah diberikan treatment

\begin{tabular}{cccc}
\hline Aspek & Sebelum & Setelah & $\begin{array}{c}\text { Persentase } \\
\text { Peningkatan }\end{array}$ \\
\hline Simulasi gerakan & $40 \%$ & $65 \%$ & $25 \%$ \\
Pembuatan jus & $40 \%$ & $70 \%$ & $30 \%$ \\
Monitor pengisian jadwal & $30 \%$ & $60 \%$ & $30 \%$ \\
\hline
\end{tabular}

Berdasarkan tabel di atas, peningkatan aspek simulasi latihan progressive muscle relaxation yaitu $25 \%$ dari $40 \%$ menjadi $65 \%$. Sedangkan, pemahaman peserta dalam pembuatan jus herbal dengan benar meningkat yaitu $30 \%$ dari $40 \%$ menjadi $70 \%$. Aspek monitor pengisian jadwal minum obat untuk keluarga yang memiliki kanker payudara juga meningkat yaitu 30\% dengan persentase sebelum diajarkan $30 \%$ dan setelahnya menjadi $60 \%$. Hasil penelitian didapatkan bahwa latihan progressive muscle relaxation juga dapat meningkatkan efikasi diri pada pasien kanker sehingga dapat dijadikan metode alternatif untuk relaksasi (Handian et al., 2018) (Smeltzer et al., 2010).

Dengan hasil tersebut dapat terlihat bahwa pelaksanaan FARKOM untuk kelompok keluarga penderita kanker payudara memiliki manfaat untuk perubahan yang lebih baik untuk pasien kanker payudara. Terlepas dari hal tersebut terdapat faktor pendukung dan hambatan dalam pelaksanaan kegiatan. Dukungan dari ketua Forum Kesehatan Kelurahan menjadi salah satu faktor pendukung terlaksananya kegiatan pengabdian masyarakat ini. Para peserta pun sangat antusias dalam mengikuti kegiatan karena menyadari betul akan manfaat yang mereka dapatkan untuk keluarganya yang mengalami kanker payudara.

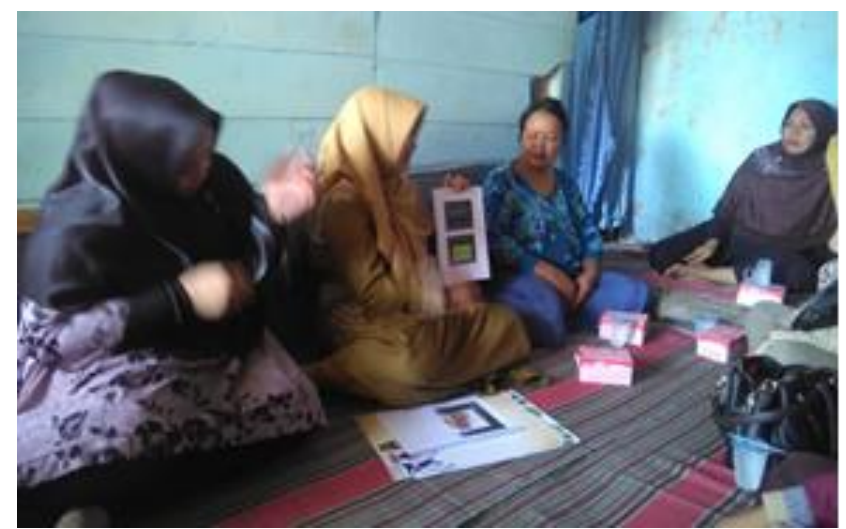

Gambar 1. Pendampingan Keluarga dalam kegiatan FARKOM

Peserta (Kelompok keluarga) berkomitmen untuk saling mendukung keluarganya yang mengalami kanker payudara dalam memberikan dukungan dan motivasi terhadap keluarganya agar tidak mengalami depresi. Hasil pengabdian ini juga didukung oleh hasil penelitian tentang dukungan sosial pada pasien kanker payudara, hasilnya bahwa $75 \%$ keluarga memberikan 
dukungan penuh pada pasien (Wahyuningsih et al., 2019). Hambatan yang ditemui tim pelaksana ketika di lapangan adalah hari pelaksanaan monitoring yang tidak bisa dalam satu waktu semua peserta, sehingga tim pelaksana mendatangi rumah keluarga satu per satu.

\section{KESIMPULAN}

Dari program FARKOM yang dilakukan di Kelurahan Bandarharjo yaitu khususnya pada keluarga dengan penderita kanker payudara diketahui bahwa program tersebut dapat meningkatkan wawasan, pengetahuan dan ketrampilan masyarakat dalam mempraktekkan latihan progresive muscle relaxation, pembuatan jus heral dan pembuatan jadwal minum obat. Program FARKOM merupakan terapi alternatif yang memiliki kebermanfaatan yang tinggi untuk pedoman keluarga dalam merawat anggota keluarga yang didiagnosis kanker payudara.

Program ini sebaiknya dapat berlangsung dan dilaksanakan secara rutin, maka besar kemungkinan peserta lebih banyak dicakupan wilayah yang lebih luas, karena pasien dengan kanker payudara terus meningkat totalnya setiap tahun. Program ini memberikan dampak positif yang besar kepada kelompok keluarga kanker payudara untuk menekan angka kesakitan selama menjalani tratmen pasien kanker.

\section{UCAPAN TERIMA KASIH}

Terimaksih kepada LPPM Universitas Islam Sultan Agung Semarang (UNISSULA) serta semua pihak yang telah membantu selama kegiatan pengabdian masyarakat berlangsung.

\section{DAFTAR RUJUKAN}

Avisha, R. N., Rochmah, H., Camelia, R., Isnaeni, Isnaini, B., \& Nisa, C. (2017). Pelatihan Manajemen Gizi Dan Perawatan Paliatif Pada Relawan Rumah Singgah Sedekah Rombongan Semarang. Jurnal Info, 19(2), 85-94. https://ejournal2.undip.ac.id/index.php/info/article/view/2196

Friyanti, E. S. (2015). Analisis kualitas dan kuantitas tenaga keperawatan terhadap persepsi insiden keselamatan pasien di Rumah Sakit $\mathrm{X}$ Jakarta Tahun 2015. Jurnal ARSI, 2(1), 43-52.

Handian, F. I., Maria, L., \& Samtyaningsih, D. (2018). Pelatihan terapi relaksasi otot progresif bagi relawan kanker untuk meningkatkan status kesehatan orang tua. Seminar Nasional Sistem Informasi (Senasif), 1463-1469.

https://jurnalfti.unmer.ac.id/index.php/senasif/article/view/196

Husni, M., Romadoni, S., \& Rukiyati, D. (2015). Hubungan Dukungan Keluarga dengan Kualitas Hidup Pasien Kanker Payudara di Instalasi Rawat Inap Bedah RSUP Dr. Mohammad Hoesin Palembang Tahun 2012. Jurnal Keperawatan Sriwijaya, 2(2), 77-83. 
Janitra, F. E., Wijayanti, K., Wahyuningsih, I. S., \& Apriyanti, H. W. (2020). Peningkatan Kualitas Hidup Pasien Kanker Payudara Melalui Program BESTCARE (Breast Cancer Wound and Palliative Care). Jurnal Inovasi Hasil Pengabdian Masyarakat (JIPEMAS), 3(1), 46-53. https://doi.org/10.33474/jipemas.v3i1.4847

Larasati, A. D., Anggorowati, \& Johan, A. (2019). Manfaat Progressive Muscle Relaxation (PMR) sebagai intervensi keperawatan dalam meningkatkan Quality of Life (QOL) wanita kanker payudara yang menjalani kemoterapi. Indonesian Journal of Nursing Research (IJNR), 2(1), 63-74. http://jurnal.unw.ac.id:1254/index.php/ijnr/article/view/233

Manafe, D. (2019). Prevalensi Kanker di Indonesia Meningkat. Berita Satu. https://www.beritasatu.com/kesehatan/535688-prevalensi-kanker-diindonesia-meningkat

Mitchell, M. L., \& Chaboyer, W. (2010). Family Centred Care-A way to connect patients, families and nurses in critical care: A qualitative study using telephone interviews. Intensive and Critical Care Nursing, 26(3), 154-160. https://doi.org/10.1016/j.iccn.2010.03.003

Onishi, K. (2016). Complementary Therapy for Cancer Survivors: Integrative Nursing Care. Asia-Pacific Journal of Oncology Nursing, 3(1), 39. https://doi.org/10.4103/2347-5625.178170

Pratitis, N. (2016). Efektivitas Problem Solving Training untuk Menurunkan Stres Perawatan pada Family Caregiver Pasien Paliatif. Persona:Jurnal Psikologi Indonesia, 5(03), 204-214. https://doi.org/10.30996/persona.v5i03.850

Rahayuwati, L., Ibrahim, K., \& Komariah, M. (2017). Pilihan Pengobatan Pasien Kanker Payudara Masa Kemoterapi: Studi Kasus. Jurnal Keperawatan Indonesia, 20(2), 118-127. https://doi.org/10.7454/jki.v20i2.478

Smeltzer, S. C., Bare, B., Hinkle, J. L., \& Cheever, K. H. (2010). Brunner and Suddarth's Textbook of Medical-Surgical Nursing. Lippincott William \& Wilksins.

Wahidin, M. (2015). Deteksi Dini Kanker Leher Rahim dan Kanker Payudara di Indonesia 2007-2014. Buletin Jendela Data Dan Informasi Kesehatan, 1(0), 12-15. https://www.kemkes.go.id/resources/download/pusdatin/buletin/buletinkanker.pdf

Wahyuningsih, I. S., Janitra, F. E., Wijayanti, K., \& Susanti, H. (2019). Protret Dukungan Keluarga pada Pasien Kanker yang Menjalani Kemoterapi. The 10th University Research Colloqium 2019, 963-967. http://repository.urecol.org/index.php/proceeding/article/view/750

Widyatuti. (2008). Terapi Komplementer Dalam Keperawatan. Jurnal Keperawatan Indonesia, 12(1), 53-57. https://doi.org/10.7454/jki.v12i1.200 